\title{
A fenomenologia de Edmund Husserl como método para a psicologia
}

\author{
Edmund Husserl's phenomenology as a method for psychology
}

\section{Arilço Chaves Nantes}

Resumo: Este artigo segue o formato de revisão bibliográfica sobre a temática da fenomenologia de Husserl (1859-1938). Esta nova abordagem apresenta-se como um dos movimentos filosóficos mais importantes do século $X X$, que desde os seus primórdios guardou relações de proximidade com a recém-criada Psicologia. Husserl se fundamenta em seu mestre Franz Brentano e sugere um novo método de conhecimento destacando fundamentalmente os fenômenos psíquicos. A fenomenologia de Edmund Husserl é uma proposta metodológica que oferece bases para uma nova abordagem do conhecimento. Esta nova gnosiologia surge como uma crítica ao paradigma científico que se mostrava incapaz de responder às demandas do conhecimento. A perspectiva fenomenológica se distancia dos métodos positivistas tradicionais por observar o fenômeno sem a realização de um recorte. Entre os principais conceitos abordados por Husserl em sua proposta fenomenológica destacaremos os termos intencionalidade e redução, importantes conceitos que podem ser aplicados à investigação psicológica.

Palavra-chave: Husserl; Fenomenologia; Psicologia.
Abstract: Abstract: This article follows the bibliographic review format on the theme of Husserl's phenomenology (1859-1938). This new approach presents itself as one of the most important philosophical movements of the twentieth century, which has maintained close relations with the newly created psychology since its beginnings. Husserl is based on his master Franz Brentano and suggests a new method of knowledge, fundamentally highlighting psychic phenomena. Edmund Husserl's phenomenology is a methodological proposal that provides the basis for a new approach to knowledge. This new gnoseology emerges as a criticism of the scientific paradigm that proved to be incapable of responding to the demands of knowledge. The phenomenological perspective distances itself from the traditional positivist methods by observing the phenomenon without making a cut. Among the main concepts addressed by Husserl in his phenomenological proposal, we will highlight the terms intentionality and reduction, important concepts that can be applied to psychological investigation.

Keyword: Husserl; Phenomenology; Psychology.

\footnotetext{
Doutorando em Psicologia pela Universidad de Ciências Empresariales y Sociales (UCES) - Buenos Aires/Argentina. Padre. E-mail: arilcosophos@gmail.com .
} 


\section{Introdução}

A fenomenologia é um termo derivado da palavra phainomenon, o que se mostra a partir de si mesmo, e logos, termo utilizado para indicar estudo, ou seja, em sua etimologia, fenomenologia é o estudo ou ciência de um fenômeno que se revela por si mesmo (Ales, 2006).

0 contexto histórico da ciência em que surge a fenomenologia, resumidamente pode ser expresso num cenário acentuadamente positivista, que rejeitava a experiência do sujeito, que centrava a atenção no naturalismo que encontrava na dinâmica da causalidade como princípio investigativo.

Husserl defendia a premissa de que a ciência de seu tempo nada poderia dizer sobre os problemas tipicamente humanos por não considerar as formas de subjetividade, que para ele incorria na perda de sentido das ciências para a vida. Sendo assim, era necessário oferecer um novo modo de produzir conhecimento que identificasse e recuperasse o sentido o que torna verdadeiramente o homem humano.

Edmund Husserl (1859-1938) foi o grande precursor da fenomenologia propondo o retorno às coisas mesmas, o encontro da sua essência, a dinâmica relacional da consciência e as vivências do fenômeno como marcas profundas de sua pesquisa.

Pode-se afirmar que a fenomenologia se preocupa com a constituição dos fenômenos, do mundo e uma de suas conclusões é que o conhecimento está na aparência dos fenômenos, e não apenas por trás deles.

Quando se afirma que o conhecimento se encontra na aparência e não apenas para além do fenômeno, conclui-se que há verdade também na própria aparência de um evento, pois as realidades fenomênicas ao mesmo tempo que revelam, ocultam, ou seja, a percepção dos eventos é possível devido a aparência e não apesar dela (Giorgi, 1978).

A fenomenologia apresenta-se como uma critica e questiona o conhecimento vigente, pois, enquanto ciência do método, engendra em si o desejo de descortinar os fenômenos tal qual ela se apresenta aos sentidos.

De acordo com a afirmação anterior, o grande esforço da fenomenologia reside na tentativa de um retorno às coisas mesmas, apreender o mundo tal qual este sempre se apresenta para nós enquanto fenômeno, pois podemos captar as coisas através de um olhar ingênuo, na expressão do próprio Husserl, olhar e ver e não simplesmente olhar e achar algo.

Husserl percebia que o mundo sensível, as experiências da vida, não podiam ser abarcadas pelas ciências da natureza e que era indispensável apreender o mundo vivido pela experiência, pela descrição do fenômeno que emerge e se revela a consciência (Silva, 2009).

É indispensável mencionar Edmund Husserl ao referir a temática da fenomenologia, pois este grande pensador situa-se nas ráizes e fundamentos deste método vigoroso.

Dentre as várias abordagens filosóficas do século XX, a fenomenologia aparece como uma das principais e importantes devido ao fato de que muitos filósofos se valeram do método fenomenológico como fundamento para pensar e elaborar suas obras filosóficas.

A fenomenologia elaborada por Husserl, segundo Lima (2014), foi decisiva para muitos autores, dentre eles, Max Scheler, Heidegger, Sartre, Merleau-Ponty, Lévinas e outros desenvolveram suas filosofias à luz desse método investigativo, que nas palavras de Heidegger em Ser e tempo (1989), referia-se a fenomenologia, como antes de tudo, um conceito de método.

Dentre várias definições ao termo fenomenologia, podemos afirmar que se trata um amplo movimento científico e espiritual, muito variado e ramificado, ainda hoje vivo e atuante, que encontra suas raízes em Edmund Husserl.

Ainda que a fenomenologia tenha tomado rumos diferentes, enquanto paradigma filosófico, ela está intimamente ligada a Edmund Husserl que Ihe atribuiu um novo significado criando um movimento que influenciou grande parte da filosofia no século XX (Lima, 2014).

A fenomenologia se ocupa pelos modos aos quais as coisas se manifestam ao homem, com sua forma, estrutura de manifestação, interrogando-se como tal experiência é processada pela consciência.

Um dos importantes objetivos da fenomenologia em Husserl consiste na identificação daquilo que é revelado na sua pureza absoluta, aquilo que aparece em si mesmo enquanto revelado à consciência, pois, para Toledo (2016), retornar às coisas mesmas possibilitam a construção do conhecimento a partir de sua realidade, compreendendo melhor o seu sentido.

A proposta Husserliana consiste em dar-se conta de como o fenômeno é percebido pelo observador, que por sua vez deve desconsiderar seus pré-conceitos para enxergar o que se mostra a partir do que se mostra por si mesmo e não a partir de seus pré-conceitos.

Na compreensão de Futura (2018), a fenomenologia éa ousada e difícil tentativa de retornar às coisas mesmas, permitindo que os fenômenos se manifestem a partir de si mesmos, pois somente assim é possível produzir um novo tipo de conhecimento.

\section{A fenomenologia de Edmund Husserl: a proposta de um método rigoroso para as ciências humanas.}

A fenomenologia pode ser identificada como um método por ser ela um caminho da crítica do conhecimento e por objetivar alcanç̧ar a ciência da essência do conhecimento ou uma doutrina universal das essências (Amatuzzi, 2009).

0 desenvolvimento do método fenomenológico de Husserl, ao menos até 0 início da década de 1920, encaminhava-se para a consolidação da filosofia como ciência fundamental, filosofia primeira, que possibilitasse uma crítica e uma nova proposta sobre a qual se assentava os fundamentos da possibilidade do conhecimento.

Uma das muitas intuições e originalidades de Husserl é retorno aos dados primordiais da experiência, o que implicava voltar às próprias coisas, pois os fenômenos são sempre anteriores às teorias, aos conceitos e possuem natureza própria.

A fenomenologia de Husserl apresenta-se como um método rigoroso que objetiva alcançar o conhecimento das essências mediante um retorno ao ponto de partida inicial, ou seja, retornar às origens, às coisas mesmas, ao fenômeno ao qual se tem acesso imediato.

Nesse método, Husserl apresenta os conceitos de intencionalidade, isto é, toda consciência é consciência de alguma coisa. Em termos husserlianos, a epoché, ou suspensão provisória do juízo, permite que o fenômeno seja per- 
cebido, apreendido e analisado sem ideias pré-concebidas, sem preconceitos ou julgamento de valor e juízo de validade.

0 método fenomenológico proposto por Husserl, segundo Maia (2017), pode ser dividido em dois momentos fundamentais: a) um deles é a fase descritiva, onde se concentra toda atenção em recolher os dados acerca do fenômeno observado tal como é apresentado mediante o relato da experiência com base no que pensam e refletem; b) Em seguida emerge a dimensão intersubjetiva onde se alcança conhecimentos generalizáveis e sujeitos à crítica entre pares.

A fenomenologia enquanto método rigoroso para as ciências, propõe que o conhecimento se produz de modo processual e relacional por que a todo instante estamos nos constituindo como sujeitos, elaborando o mundo, logo, nossa consciência e mundo se constituem num só e mesmo ato.

Um dos principais objetivos da fenomenologia enquanto método, conforme Alencar (2015), é a descrição da estrutura total da experiência vivida captando os significados que a experiência tem para os sujeitos que a vivenciam, como tais eventos se apresentam, enfatizando a apreensão e compreensão do mesmo, e não apenas sua explicação pormenorizada.

A fenomenologia enquanto ferramenta de conhecimento intenta observar o fenômeno, a partir dele mesmo, em direção a um sentido, procurando não acrescentar um saber a priori, pois a finalidade da fenomenologia enquanto ciência da descrição de eventos é capturar as vivências, bem como sua relação com o meio (Futura, 2018).

0 pesquisador que observa determinado fenômeno, percebe o observável como alguém de fora, mas também como alguém de dentro, pois aquele que observa e descreve comporta-se como representante de um aspecto do sentido do fenômeno.

Pode-se afirmar que o método fenomenológico de Husserl se propõe a uma nova formulação de uma teoria do conhecimento, ou seja, é uma pergunta sobre os modos de como se conhece a realidade, atitude que está implicada no modo como vivemos cotidianamente com a realidade externa onde nos encontramos e tomamos como referência, por isso que a fenomenologia é também um modo de vida.

A fenomenologia como modo de vida, propõe perceber os eventos a partir deles mesmos, pois este retornar às coisas mesmas situa-se entre 0 discurso especulativo da metafísica e o raciocínio das ciências positivas. Uma vez que ocorre a apreensão do fenômeno a partir de si mesmo, torna-se possível o encontro da essência, emergindo que faz tal fenômeno ser ele mesmo e não outra realidade.

A fenomenologia é um modo de vida presente no cotidiano para Zilles (2007), porque grande parte das vivências humanas não se opera de modo isolado e fora do mundo, mas em relação, em interação, pois as experiências produzem-se no espaço e no tempo, de modo que nossas lembranças, pensamentos, julgamentos, valores e desejos operam num ato relacional.

A fenomenologia como nova teoria do conhecimento em Husserl, inicialmente parte do conceito de atitude natural, ou seja, da crença no mundo da onde vivemos, nos movemos e somos cotidianamente, onde o mundo é a realidade espaço-temporal onde nos encontramos e tomamo-lo como referência principal (Zilles, 2007).

Uma das principais críticas de Husserl à ciência de seu tempo é que esta não possuía a percepção que os fenômenos partiam do mundo no qual as coisas circundantes estavam disponíveis, livres ainda de qualquer desenvolvimento teórico. Partir, ou retornar aos eventos mesmo é uma expressão recorrente no pensamento de Husserl.

Ao tratar sobre Husserl e sua fenomenologia enquanto método muito poderia ser dito, mas iremos nos deter em apenas dois conceitos importantes que são: redução fenomenológica e intencionalidade.

\section{A redução fenomenológica (epoché): uma breve introdução ao termo}

A redução fenomenológica em Husserl significa pôr entre parênteses, pôr em suspensos os conhecimentos a priori, valendo-se do recurso da dúvida universal cartesiana, não no sentido de duvidar da existência, mas sim de questionar se o que se apresenta à minha percepção é de fato o que 0 fenômeno é em si ou algo diferente, por isso, é preciso colocar entre parênteses os próprios conceitos, abster-se qualquer pré-julgamento sobre daquilo que parece estar diante de nós.

A atitude de redução enquanto ferramenta metodológica não significa adotar uma atitude ceticista frente à realidade do mundo, mas possibilita focalizar a atenção nos objetos dos quais temos consciência, para o modo como temos consciência desses mesmos objetos. 0 objetivo passa a ser os atos da consciência, desvinculado de toda a questão de, se as coisas sobre as quais pensamos existem de fato na realidade fora de nós.

A epoché enquanto atitude metodológica não consiste na dúvida radical cartesiana, pois não se está duvidando do mundo, mas sim, tomando uma posição de abstenção de juízo.

Mesmo que Husserl tenha profunda estima por Descartes e elogie seu método, ele sustenta que a fenomenologia parte de um procedimento semelhante, embora, não produza os mesmos resultados, nem tampouco a mesma intenção, pois Descartes partia da dúvida radical para, logo em seguida, de posse de uma justificação, reafirmar toda a realidade da natureza objetiva, ao passo que a redução fenomenológica coloca em parênteses o objeto investigado, mas não concebe o objeto como não existente, apenas assume uma nova perspectiva para que o ser do objeto se torne visível (Cormanichi, 2017).

A atitude fenomenológica de redução implica que não se deve fazer juízo algum sobre o mundo, sobre tudo aquilo que nele se inclui, ainda que nos sejam disponibilizadas as mais convincentes evidências sobre determinado dado, logo, tudo precisa ficar em suspenso, por decidir, e este pôr em suspenso é de certa forma um método redutivo que encaminha para a operacionalização da redução.

Ao se realizar a atitude de epoché, reduz-se as vivências à sua essência (eidos), uma vez que os objetos ideais, para Futura (2018), não se encontram na mente, nem no mundo platônico das ideias e nem mesmo na inteligência divina.

A importância desta atitude de redução reside no fato de se colocar em suspensão as ideias pré-concebidas sobre o fenômeno no espaço e/ou no tempo, de modo que emerja as variadas formas de como o fenômeno surge no mundo, sem acrescer ou eliminar nada.

Este primeiro momento da redução fenomenológica pode ser chamado de redução psicológica, onde coloca-se o fenômeno entre parênteses, pos- 
sibilitando perceber que tal realidade se apresenta num processo consciente sendo notado de modo múltiplo, diverso.

A redução psicológica tem seu foco na apreensão interior, com a percepção que se mostra no interior do sujeito que analisa o fenômeno, ou seja, realiza-se a redução apenas com a finalidade de considerar a realidade destes dados imanentes presentes na consciência do observador (Nachmanowicz, 2007).

Com a redução psicológica, segundo Lima (2009), produz-se uma espécie de corte entre a região da consciência e a região do mundo onde a suspensão de juízo opera como um momento de recuo e descobre-se, através desse recuo aquém ou além, mas não no mesmo plano do fenômeno, ou seja, há uma separação entre fato e essência.

\section{A intencionalidade da consciência em Edmund Husserl: breves conceituações}

A expressão intencionalidade Husserl tomou-a por empréstimo da psicologia descritiva de Franz Brentano, grande influenciador de sua obra que afirmava ser toda consciência, consciência de algo distinto dela mesma, por isso toda vivência é constituída pelo sujeito de forma intencional como uma efetuação consciente através de suas vivências.

Consciência e objeto, não podem ser compreendidos como duas realidades separadas, independentes, mas sim em profunda e contínua relação, articulação, definindo-se respectivamente, não sendo possível a existência de ambos sem a dinâmica relacional (Dartigues, 1992).

A consciência não deve ser compreendida como um lugar físico, psíquico ou espiritual, mas sim como uma realidade de convergências das ações do homem, algo intencional, sempre dirigida à algo, para a transcendência, para as coisas, para as pessoas, para as ações, para tudo o que diz respeito ao humano. É o que afirma (Demarchi, 2013).

A consciência intencional permite ao fenômeno emergir como significação, faz com que se manifestem mediante sua intencionalidade, promovendo também a possibilidade da constituição das coisas (Goto, 2011). A noção de intencionalidade refere-se ao intenso transcender de si mesmo, experiência esta recorrente na vida humana, pois a cada instante temos que nos posicionar frente às coisas, logo a consciência é sempre ativa, confere sentido às coisas e atribui significados no mundo.

Esta intencionalidade, para Holanda (1997), é a característica prática mais fundamental da fenomenologia de Husserl, pois a consciência ativa não ocorre no vazio, está sempre orientada a um objeto, oportunizando à consciência sair de si mesma em direção ao fenômeno, gerando uma correlação entre os atos de consciência e os objetos constituídos por esses atos, pois, consciência e objeto não são duas realidades dicotômicas, mas existem em relação contínua.

A intencionalidade em Husserl é sempre significativa, não reduzida apenas a um caráter físico, mas como uma unidade, sendo composta basicamente por três elementos que são: a) consciência como consciência fenomenológica do real como uma espécie de entrelaçamento das vivências psíquicas na unidade do seu curso; 2) a consciência como percepção interna das vivências psíquicas próprias; 3) a consciência como nome coletivo para a dita classe de atos psíquicos ou vivências intencionais (Campos, 1945).
Sendo assim, a intencionalidade é uma relação dialética, pois existimos no mundo, afetamos e somos continuamente afetados, vivências e pensamentos encaminham-nos a um sentido.

Conforme Husserl (1989), o sentido e o significado processados pela consciência, conferem uma orientação ao objeto, pois a consciência produz equilíbrio entre a eidética e a consciência transcendental instaurando várias realidades, construindo uma relação interacional onde o significado abarca um grande número de vivências.

A intencionalidade significa um direcionamento da consciência em relação ao objeto, pois a consciência é sempre consciência de al guma coisa, objeto é sempre objeto para uma consciência. Sem esta relação consciência e objeto não existiriam, uma vez que, para Brandes, (2017), a consciência visa alguma coisa por que já traz em si seu objeto receptivo, logo, todo querer, todo desejar, todo sentir corresponde a algo querido, a algo desejado e a algo sentido.

A teoria da intencionalidade em Husserl aponta para o fato de que enquanto consciência estamos sempre direcionados para objetos reais, que vivenciamos situações diretas e não meramente representativas, que as vivencia ocorrem no presente, que os eventos se fazem presente de modo inédito.

A tese Husserliana da consciência intencional indica que sempre intencionamos algo, pois, conforme Brandes (2017), há no âmago da consciência humana um plêiade de sensações que de per si não direcionam para objeto algum, logo, é possível que haja experiências na consciências sem que este mesmo dado possa existir na exterioridade.

0 conceito de intencionalidade da consciência, na opinião de Siani, Correa e Las Casas (2016), expressam a não existência de objetos em si mesmos, separados, para posteriormente depois se unirem, ligarem uns aos outros, mas que ambas se encontram em intensa relação de intenção, onde ser na consciência significa existir no mundo.

Franz Brentano (1838-1917), mestre de Husserl, afirmava que os dados da consciência são formados em duas grandes classes que são: as categorias dos fenômenos físicos e os fenômeno mental, havendo uma destacada relação intencional entre atos mentais e seus objetos (Toledo, 2016).

A intuição brentaniana afirmava que os fenômenos mentais são atos mentais direcionados intencionalmente para os seus objetos, ou fenômenos físicos, mas que os dados da mente podem vir a ser objetos de outros atos mentais, sendo assim, fenômenos mentais e fenômenos físicos se articulam intencionalmente entre si.

Husserl herda de Brentano a noção de intencionalidade como sendo do fenômeno psíquico identificado pelo que os escolásticos da Idade Média chamaram de inexistência intencional, pois, segundo eles, eventos possuem em si algo a título de objeto, mas não da mesma maneira.

Nas representações mentais, como sublinha Brentano (1944), há sempre realidades que existem fora da mente, no mundo real, de modo que no amor há sempre algo do amado, no ódio sempre algo do que é odiado, no desejo há sempre algo do desejado, por isso nos fenômenos sempre há algo intencionalmente voltado ao objeto.

Em Brentano (1944), a intencionalidade é um traço exclusivamente pertencente ao mundo dos eventos psíquicos, ao passo que para os eventos concernentes à realidades físicas, tal premissa não pode ser aplicada, mesmo porque eventos psíquicos se orientam para objetos físicos, mas fenômenos psíquicos são os atos de ver, ouvir, falar, ao passo que eventos físicos representam o modo como são vistos, ouvidos e falados. 


\section{O legado da fenomenologia de Edmund Husserl para a pesquisa em psicologia}

A fenomenologia em Husserl propõe-se em responder pela pergunta de um método rigoroso em resposta à crise das ciências europeias, que de per si representava também uma crise das subjetividades, bem como uma crise da cultura.

Esta fenomenologia enquanto método propõe um novo modo de ver e situar-se no tempo e espaço, pautando-se num grande esforço de contemplar a vida autêntica que não se encontra fora da consciência, mas dentro da mesma.

A relação entre psicologia e fenomenologia, conforme Futura (2018), é de grande proximidade para Husserl que ao tecer críticas à psicologia enquanto ciência positiva, apontando para uma psicologia fenomenológica, que para ele deve considerar a subjetividade como seu objeto, contradizendo o modelo de ciência vigente que notava a subjetividade como algo negativo ao conhecimento.

Para Husserl, a fenomenologia é adotada como método à psicologia colocando a subjetividade no centro, ou seja, as vivências subjetivas são 0 objeto principal da ciência psicológica.

No Brasil, Castro e Gomes (2011), afirmam que a utilização da fenomenologia como método para a psicologia teve seu início 1948, quando Nilton Campos apresentou sua tese de doutorado sobre o método fenomenológico. Ainda assim, somente a partir da década de 1970 é que a fenomenologia enquanto método rigoroso é aplicado nas pesquisas em psicologia.

A perspectiva fenomenológica se distancia dos métodos positivistas tradicionais, para Holanda (2002), porque observa o fenômeno sem a realização de um recorte, analisando a experiência, resgatando o vivido, desvelando 0 significado que os indivíduos atribuem a sua vivência.

Uma investigação fenomenológica, de acordo com Bruns e Holanda (2001), é uma pesquisa de natureza que pretende dar conta do que ocorre mediante o clareamento do fenômeno, não como verificação, mas como compreensão de algo, tomado em sua intencionalidade.

Na pesquisa fenomenológica o pesquisador atua como facilitador do acesso ao vivido, sendo de grande relevância, pois muitas vezes, a pessoa ainda não teve oportunidade de falar sobre suas vivências, sendo que, no diálogo com o pesquisador, este indivíduo acessa conteúdos até então desconhecidos, verbalizando expressões como as seguintes: não havia pensado nisso, antes não tinha notado tal situação!

Na perspectiva fenomenológica a consciência se encontra atrelada ao conceito de intencionalidade, de sentido, de existência, ultrapassando uma mera relação cognitiva de sujeito como uma relação existencial do sujeito com seu mundo, até por que, o existir humano é o modo pelo qual as pessoas se posicionam diante da vida (Giorgi, 1978).

A psicologia de aporte fenomenológico recolheu importantes contribuições de Edmund Husserl, dentre eles, um grande cuidado quanto à descrição dos fenômenos, a atitude redução (epoché), e a procura pelas essências. De modo muito sintético e breve, este é um dos legados husserlianos para a psicologia (Giorgi, 2010).

\section{Considerações finais}

A fenomenologia em Husserl propõe um novo olhar, um novo modo de perceber a realidade pautando-se pela premissa inicial de que se deve pôr em suspenso todos a priori, banhar-se no esquecimento de todas as interpretações do mundo e ver o que se mostra sem impregnações artificiais.

Husserl e sua proposta fenomenológica pretendem realizar um retorno às coisas mesmas, vê-las a partir delas, por isso propõe um método que inaugura um novo tipo de conhecimento, o conhecimento compreensivo, deixando de lado o conhecimento explicativo-causal-dedutivo e oferecendo o conhecimento fenomenológico-descritivo-compreensivo.

Uma das originalidades de Husserl foi notar que os fenômenos se mostram de múltiplas maneiras e que o mostrar-se depende sempre de um horizonte compreensivo que os acolhe. Husserl compreendeu que a descrição fenomenológica não é mera descrição dos aspectos sensoriais, mas descrição da experiência, da vivência de alguém que pertence a um determinado contexto no qual este fenômeno aparece.

A fenomenologia e sua aplicabilidade na psicologia, nas palavras de Holanda (1997), éantes de tudo uma postura, uma atitude que descortina um gama de possibilidades para que o encontro com o fenômeno se torne pleno, sendo um observador atento que participa mas não interfere, permitindo que o fenômeno se manifeste em sua inteireza e riqueza.

Talvez uma das maiores contribuições de Husserl e sua proposta fenomenológica para a psicologia foi chamar a atenção para o mundo vivido, 0 cotidiano onde a vida transcorre, pois ele é o palco onde todas as atividades humanas acontecem.

As vivências cotidianas vem anteriormente a qualquer elucubração, existem antes de nós, continuarão após nossa interpretação, por isso, devem ser a base de todo o conhecimento, uma vez que o homem constrói as suas vivências à medida que experimenta o mundo (Gomes, 2015).

A fenomenologia enquanto método aplicado à psicologia é uma modalidade de pesquisa qualitativa que busca compreender o fenômeno interrogado, partindo do mundo-vida dos sujeitos que vivenciam tal fenômeno que será pesquisado, considerando suas próprias experiências para investigar o mundo circundante.

0 método fenomenológico pauta-se por uma abordagem descritiva, permitindo que o fenômeno se manifeste a partir de si no intuito de atingir o sentido da experiência, identificando as vivências das pessoas envolvidas no evento, descrevendo de forma compreensiva o relato, atingindo assim a essência ou estruturas das experiências, conforme afirmação de Giorgi (1978).

\section{Referências}

Alencar, B. R. (2015). Ser-com no voluntariado: o cuidar na perspectiva da fenomenologia existencial. Dissertação (Mestrado em Psicologia), apresentada à Universidade Federal do Amazonas - UFAM. Área de Concentração: Psicologia). Orientador: Professor Doutor Ewerton Helder Bentes de Castro. Ales, B. Â. (2006). Introdução à fenomenologia. Bauru, SP: Eduse.

Amatuzzi, M. M (2009). Pesquisa fenomenológica: uma aproximação teórico humanista. Estudos de Psicologia (Campinas), 26 (1).

Brandes, L. M. S. (2017). O conceito de intencionalidade na quinta investigação de Edmund Husserl (1859-1938). G. Porta. (Dissertação de Mestrado). Faculdade de Filosofia - Pontifícia Universidade Católica de São Paulo. São Paulo. 
Brentano, F. (1944). Psychologie du point de vue Empirique. Tradução: Maurice de Gandillac. Paris: Aubier,

Campos, N. O. Método fenomenológico na psicologia (1945). Tese de Concurso apresentado à Cátedra, Universidade do Brasil, Rio de Janeiro.

Castro, T. G.; Gomes, W. B. Movimento fenomenológico: controvérsias e perspectivas. Psicologia: teoria e pesquisa, 27(2), 233-240.

Cormanich, E. L. (2017). 0 conceito de psicologia fenomenológica em Husserl. Dissertação de Mestrado), Programa de Pós-graduação em Psicologia, Universidade Federal de Juiz de Fora. Minas Gerais, Juiz de Fora.

Dartigues, A. (1992). O queé a fenomenologia? Tradução de Maria José J. G. de Almeida. (32. ed.) São Paulo: Editora Moraes.

Demarchi, L. (2013). A concepção sobre ser humano para o discente do curso de administração: aproximaçôes com a fenomenologia de Edith Stein. Dissertação (Mestrado em Administração). Faculdade de Administração e Economia da Universidade Metodista de São Paulo). São Bernardo do Campo, São Paulo.

Futura. O método fenomenológico (2018). Material Didático. Votuporanga, SP.

Giorgi, A. (1978). Psicologia como Ciência Humana: uma abordagem de base fenomenológica/ Amedeo Giorgi. Tradução de Riva S. Schartzman. Belo Horizonte.

Giorgi, A.; Souza, D. Método fenomenológico de investigação em psicologia. Lisboa: Fim de Século, 2010.

Gomes, K.K.A (2015). Ea vida sofre transformações: compreendendo a vivência de crianças com câncer à luz da psicologia fenomenológico-existencial. Dissertação (Mestrado em Psicologia), Universidade Federal do Amazonas). UFAM, Manaus.

Heidegger, M. (1998). Ser e tempo. Petrópolis, Rio de Janeiro: Vozes, 2 vols.

Goto, T.A. (2007). A (Re) constituição da psicologia fenomenológica em Edmund Husserl/Tommy Akira Goto. Campinas: PUC-Campinas.

Holanda, A. F. (1997). Fenomenologia, psicoterapia e psicologia humanista. Revista Estudos de Psicologia, 14(2), 33-46.

Husserl, E. (1929). Conferencias de Paris. Tradutores: Artur Morão e Antônio Fidalgo. Lusofia editora.

Husserl, E. (1989). A Ideia da fenomenologia. Lisboa: Edições 70. Tradução de Artur Mourão. /Fr: L'Idée de la Phénoménologie, cinq leçons. Paris: Presses Universitaires de France, 1970. Tradução de Alexandre Lowit.

Lima, A.B.M. Org. (2014). Ensaios sobre fenomenologia: Husserl, Heideggere Merleau-Ponty. [online]. Ilhéus, BA: Editus.

Maia, J. F. L. (2017). Como eu me sinto? Um estudo fenomenológico da experiência de pessoas diagnosticadas com perturbação bipolar. Dissertação de mestrado em Psicologia. ISPA. Orientador: Prof. Dro. Víctor Amorim Rodrigues. Portugal. Lisboa.

Nachmanowicz, R. M. (2007). Fundamentos para uma análisemusical fenomenológica, 144 fls.; il. Dissertação (Mestrado em Psicologia), Universidade Federal de Minas Gerais, Escola de Música Orientador, Belo Horizonte. Minas Gerais.

Siani, S. R.; Correa, D.A. (2016). Las Casas, Alexandre Luzzi. Fenomenologia, método fenomenológico e pesquisa empírica: 0 instigante universo da construção de conhecimento esquadrinhada na experiência de vida. Revista de Administração da UNIMEP - Vol.14, n.1, Janeiro/Abril.

Toledo, P. L. Y. (2016). A prática do professor de educação infantil e as interfaces com a música: uma leitura em fenomenologia. Dissertação de Mestrado, Universidade Federal de Mato Grosso do Sul, Programa de Pós- Graduação em Psicologia, Campo Grande/MS.

Zilles, U. (2007). Fenomenologia e teoria do conhecimento em Husserl. Revista da Abordagem Gestáltica, 13(2): 216-221. 